\title{
Acute Kidney Injury after Cardiac Surgery: Risk Factors and Novel Biomarkers
}

\author{
Shi-Min Yuan ${ }^{1}, \mathrm{MD}, \mathrm{PhD}$
}

DOI: 10.21470/1678-9741-2018-0212

\begin{abstract}
Acute kidney injury (AKI) is a common and severe complication after cardiac surgery. Currently, a series of novel biomarkers have favored the assessment of AKI after cardiac surgery in addition to the conventional indicators. The biomartkers, such as urinary liver fatty acid binding protein (L-FABP), urinary neutrophil gelatinase-associated lipocalin (NGAL), serum L-FABP, heart-type FABP, kidney injury molecule 1 (KIM-1), and interleukin-18 were found to be significantly higher in patients who developed AKI after cardiac surgery than those who did not. Apart from urinary interleukin-18, the novel biomarkers have been recognized as reliable indicators for predicting the diagnosis, adverse outcome, and even mortality of AKI after cardiac surgery. The timing of the renal replacement therapy is a significant predictor relating to
\end{abstract}

patients' prognoses. In patients with AKI after cardiac surgery, renal replacement therapy should be performed as early as possible in order to achieve promising outcomes. In children, AKI after cardiac surgery can be managed with peritoneal dialysis. AKI after cardiac surgery has received extensive attention as it may increase early mortality and impact long-term survival of patients as well. The purpose of this article was to analyze the changes of the pertinent biomarkers, to explore the related risk factors leading to the occurrence of AKI after cardiac surgery, and to provide a basis for the clinical prevention and reduction of AKI.

Keywords: Acute Kidney Injury. Biomarkers. Dialysis. Renal Replacement Therapy. Risk Factors.

\begin{tabular}{|c|c|c|c|}
\hline \multicolumn{4}{|c|}{ Abbreviations, acronyms \& symbols } \\
\hline ACEI & $=$ Angiotensin-converting enzyme inhibitor & IL & $=$ Interleukin \\
\hline AKI & $=$ Acute kidney injury & KDIGO & = Kidney Disease Improving Global Outcomes \\
\hline AKIN & = Acute Kidney Injury Network & KIM-1 & = Kidney injury molecule 1 \\
\hline ARB & $=$ Angiotensin II receptor antagonist & L-FABP & $=$ Liver-type fatty acid binding protein \\
\hline AUC & $=$ Area under curve & NAC & $=\mathrm{N}$-acetylcysteine \\
\hline BP & $=$ Blood pressure & NGAL & $=$ Neutrophil gelatinase-associated lipocalin \\
\hline CABG & $=$ Coronary artery bypass grafting & RAS & $=$ Renin-angiotensin system \\
\hline CPB & = Cardiopulmonary bypass & RIFLE & $=$ Risk, Injury, Failure, Loss of kidney function, and \\
\hline eGFR & $=$ Estimated glomerular filtration rate & & End-stage kidney disease \\
\hline GDF-15 & $=$ Growth-differentiation factor-15 & SAS & = Sympathetic-adrenomedullary system \\
\hline GFR & $=$ Glomerular filtration rate & $\mathrm{SCr}$ & $=$ Serum creatinine \\
\hline h-FABP & $=$ Heart-type fatty acid binding protein & TIMP-2 & $=$ Tissue inhibitor of metalloproteinases- 2 \\
\hline IGFBP7 & $=$ Insulin-like growth factor binding protein 7 & USA & $=$ United States of America \\
\hline
\end{tabular}

'Department of Cardiothoracic Surgery, The First Hospital of Putian, Teaching Hospital, Fujian Medical University, Putian, Fujian Province, People's Republic of China.

This study was carried out at the The First Hospital of Putian, Teaching Hospital, Fujian Medical University, People's Republic of China.
Correspondence Address:

Shi-Min Yuan

(iD) https://orcid.org/0000-0002-1773-2959

389 Longdejing Street, Chengxiang District, Putian, Fujian Province, People's

Republic of China

Zip code: 351100

E-mail: shiminyuan@126.com 


\section{INTRODUCTION}

Acute kidney injury (AKI) is a common and severe complication after cardiac surgery with an incidence of 3.4\%; $1.9 \%$ of which requiring dialysis treatment ${ }^{[1]}$. The incidences of $A K I$ in patients receiving isolated conventional coronary artery bypass grafting $(\mathrm{CABG})$ and off-pump coronary artery bypass are $2.9 \%$ and $1.4 \%$, respectively, with $35.8 \%(19 / 53)$ of the $\mathrm{AKI}$ patients requiring dialysis ${ }^{[2]}$. A large nationwide database analysis in the United States revealed that $C A B G$-associated $A K I$ needing dialysis had increased from $0.2 \%$ to $0.6 \%$, while the mortality simultaneously decreased from $47.4 \%$ in 1988 , to $29.7 \%$ in $2003^{[3]}$. In a retrospective cohort study of patients undergoing CABG in a single hospital in Brazil, the incidence of postoperative AKI was $9.3 \%{ }^{[4]}$. The incidence of AKI was much higher in patients receiving CABG older than 70 years than in younger patients ${ }^{[5]}$, and in patients with conventional aortic valve replacement than in those with transapical aortic valve implantation ${ }^{[6]}$. Postoperative AKI not only extends the hospitalization days and increases the expenses of the patients, but also becomes an important independent prognostic risk factor. Especially, the incidence of AKI in patients after operation for thoracic aortic dissection is relatively high, with an increased mortality ${ }^{[7]}$. It was reported that a total of $27.7 \%$ of postoperative AKI patients developed atrial fibrillation ${ }^{[8]}$. Novel biomarkers that are applied in clinical practice as early and rapid indicators of AKI after cardiac surgery greatly facilitated the assessments of the occurrence, progression, and prognosis of the patients. AKI after cardiac surgery has received extensive attention as it may increase early mortality and impact long-term survival of patients as well. The purpose of this study was to analyze the changes of the pertinent biomarkers, to explore the related risk factors leading to the occurrence of $A K I$, and to provide a basis for the clinical prevention and reduction of AKI.

\section{DEFINITIONS}

The diagnosis of AKI was based on: 1) gradually decreased urine output $<0.5 \mathrm{~mL} / \mathrm{kg} /$ hour, for consecutively three hours with a poor response to diuretics; and 2) plasma creatinine $>110$ $\mu \mathrm{mol} / \mathrm{L}$ or exceeding the baseline for over $>50 \%{ }^{[9]}$. Severe renal insufficiency is defined as an estimated glomerular filtration rate $(e G F R)<30 \mathrm{~mL} / \mathrm{min} / 1.73 \mathrm{~m}^{2[10]}$. The diagnostic criteria of AKI following cardiac surgery are a $0.3 \mathrm{mg} / \mathrm{dL}$ or $50 \%$ or higher change in serum creatinine from baseline or a reduction on urine output of $<0.5 \mathrm{~mL} / \mathrm{kg} /$ hour over a six-hour interval, within 48 hours, following adequate volume resuscitation ${ }^{[11]}$. In addition, the eGFR by inclusion of cystatin C, named as Formula of Larsson, and calculated as $99.43 \times$ cystatin $C^{-1.5837}$ can be a more sensitive indicator of renal function after cardiac surgery in comparison to creatinine and the glomerular filtration rate (GFR) per se $e^{[12]}$. The Risk, Injury, Failure, Loss of kidney function, and End-stage kidney disease (RIFLE) classification, the Acute Kidney Injury Network (AKIN) criteria ${ }^{[13]}$, and the Kidney Disease Improving Global Outcomes (KDIGO) stages ${ }^{[14]}$ are practical predictors for the evaluation of AKI after CABG and (or) heart valve operations (Table 1). The Society of Thoracic Surgeons scoring system can

Table 1. Classification systems for acute kidney injury.

\section{I: RIFLE Classification}

\begin{tabular}{l|l|l}
\hline Stage & GFR criteria & Urine output criteria \\
\hline Risk & $\begin{array}{l}\text { SCr increased } 1.5-2 \text { times baseline or } \\
\text { GFR decreased }>25 \%\end{array}$ & $<0.5 \mathrm{~mL} / \mathrm{kg} / \mathrm{hour}$ for $<6$ hours \\
\hline Injury & $\begin{array}{l}\text { SCr increased } 2-3 \text { times baseline or } \\
\text { GFR decreased }>50 \%\end{array}$ & $<0.5 \mathrm{~mL} / \mathrm{kg} / \mathrm{hour}$ for $>12$ hours \\
\hline Failure & $\begin{array}{l}\text { SCr increased }>3 \text { times baseline or } \\
\text { GFR decreased } 75 \% \text { or } \\
\text { SCr } \geq 4 \text { mg/dL; acute rise } \geq 0.5 \mathrm{mg} / \mathrm{dL}\end{array}$ & $<0.3 \mathrm{~mL} / \mathrm{kg} /$ hour for 24 hours (oliguria) or anuria for 12 hours \\
\hline Loss of function & Persistent acute renal failure: complete loss of kidney function $>4$ weeks (requiring dialysis) \\
\hline End-stage renal disease & Complete loss of kidney function $>3$ months (requiring dialysis) \\
\hline
\end{tabular}

\section{Acute Kidney Injury Network (AKIN)}

Abrupt (within 48 hours) reduction in kidney function currently defined as an absolute increase in SCr of $0.3 \mathrm{mg} / \mathrm{dL}$ or $\mathrm{more}$ ( $\geq 26.4$ umol/L) or

A percentage increase in $\mathrm{SCr}$ of $50 \%$ or more (1.5-fold from baseline) or

A reduction in urine output (documented oliguria of $<0.5 \mathrm{~mL} / \mathrm{kg} / \mathrm{hour}$ for $>6$ hours)

\section{Kidney Disease Improving Global Outcomes (KDIGO)}

Increase in $\mathrm{SCr}$ by $0.3 \mathrm{mg} / \mathrm{dL}$ or more within 48 hours or

Increase in SCr to 1.5 times baseline or more within the last 7 days or

Urine output $<0.5 \mathrm{~mL} / \mathrm{kg} /$ hour for 6 hours

$\mathrm{GFR}=$ glomerular filtration rate; RIFLE=Risk, Injury, Failure, Loss of kidney function, and End-stage kidney disease; SCr=serum creatinine 
be used for the determination of postoperative mortality and morbidity including AKI ${ }^{[15]}$.

\section{Risk Factors}

Thereareseveral possiblecauses of AKlafteropenheartsurgery, which can be classified as prerenal, renal, and postrenal causes. They can be further divided into: inflammatory, hemodynamic, constitutional and nephrotoxic (Table 2) ${ }^{[16]}$. Of them, renal perfusion deficiency subjected to sustained hypotension during the perioperative period was considered to be the main cause of AKI after cardiac surgery ${ }^{[17]}$. In a retrospective study on 108 patients with AKI after cardiac surgery, the etiologies responsible for the development of AKI included cardiogenic hypotension (46.3\%, 50/108), multiorgan failure $(2.8 \%, 3 / 108)$ (two were due to drug renal toxicity), respiratory failure $(3.7 \%, 4 / 108)$, hemolysis (7.4\%, 8/108), drug-induced interstitial pneumonia (0.9\%, 1/108), and unknown causes $(38.9 \%, 42 / 108)^{[18]}$. The predictive risk factors for postoperative severe renal insufficiency include age, gender, white blood cell count $>12,000 / \mathrm{mm}^{3}$, prior CABG, congestive heart failure, peripheral vascular disease, diabetes, hypertension, and preoperative intra-aortic balloon pump ${ }^{[19]}$. In cardiopulmonary surgery, the four most important independent risk factors for postoperative $A K I$ are old age, preoperative renal insufficiency,

Table 2. Predictive risk factors of acute renal failure after cardiac surgery.

\begin{tabular}{|c|c|c|c|c|}
\hline Type & Risk factor & Preoperative & Intraoperative & Postoperative \\
\hline \multirow{3}{*}{ Prerenal } & $\begin{array}{l}\text { 1. Renal } \\
\text { dysfunction }\end{array}$ & $\begin{array}{l}\text { - Lack of renal reserve } \\
\text { - Renovascular disorder } \\
\text { - Prerenal azotemia }\end{array}$ & - Renal perfusion deficiency & $\begin{array}{l}\text { - Renal perfusion } \\
\text { deficiency }\end{array}$ \\
\hline & 2. Hemodynamic & $\begin{array}{l}\text { - Cardiac dysfunction } \\
\text { - Cardiogenic shock } \\
\text { - Severe arrhythmias } \\
\text { - Left main coronary disease }\end{array}$ & $\begin{array}{l}\text { - Non-pulsatile flow } \\
\text { - Vasoactive agents } \\
\text { - Anesthetic effects } \\
\text { - Cardiogenic shock } \\
\text { - Severe arrhythmias } \\
\text { - Embolic events } \\
\text { - Positive end-expiratory } \\
\text { pressure }\end{array}$ & $\begin{array}{l}\text { - Low output } \\
\text { syndrome } \\
\text { - Vasoactive agents } \\
\text { - Left ventricular } \\
\text { dysfunction }\end{array}$ \\
\hline & 3. Institutional & $\begin{array}{l}\text { - Chronic obstructive pulmonary disease } \\
\text { - Diabetes } \\
\text { - Low serum ferritin }\end{array}$ & $\begin{array}{l}\text { - Hypercalcemia } \\
\text { - Hypoproteinemia } \\
\text { - Hemodilution }\end{array}$ & $\begin{array}{l}\text { - Hypercalcemia } \\
\text { - Hypoproteinemia }\end{array}$ \\
\hline \multirow{5}{*}{ Renal } & $\begin{array}{l}\text { 1. Ischemic/ } \\
\text { hypoxic }\end{array}$ & - Lung disease & $\begin{array}{l}\text { - Acute lung injury } \\
\text { - Ischemia-reperfusion injury }\end{array}$ & - Acute lung injury \\
\hline & 2. Inflammatory & - Inflammation & $\begin{array}{l}\text { - Surgical operation } \\
\text { - Cardiopulmonary bypass }\end{array}$ & $\begin{array}{l}\text { - Systemic } \\
\text { inflammation }\end{array}$ \\
\hline & 3. Endotoxic & - Endotoxemia & - Endotoxemia & - Sepsis \\
\hline & 4. Nephrotoxic & $\begin{array}{l}\text { - Intravenous contrast } \\
\text { - Angiotensin-converting enzyme } \\
\text { inhibitor (ACEI) and angiotensin II } \\
\text { receptor antagonist (ARB) } \\
\text { - Other medications } \\
\end{array}$ & - Free hemoglobin & $\begin{array}{l}\text { - Nephrotoxic } \\
\text { agents }\end{array}$ \\
\hline & $\begin{array}{l}\text { 5. Renal vascular } \\
\text { and microvascular }\end{array}$ & $\begin{array}{l}\text { - Renal artery thrombosis } \\
\text { - Takayasu arteritis involving the renal artery } \\
\text { - Renal vein thrombosis } \\
\text { - Disseminated intravascular coagulation }\end{array}$ & - Ditto & - Ditto \\
\hline Postrenal & 1. Obstructive & $\begin{array}{l}\text { - Renal pelvic and ureteropelvic junction } \\
\text { obstruction (renal calculus, malignant } \\
\text { tumors, pelvic and retroperitoneal tumor } \\
\text { compression) } \\
\text { - Urocystic unfluent urination (prostatic } \\
\text { hyperplasia or tumor, sarcoma, calculus } \\
\text { and blood clots of the bladder, and } \\
\text { neurogenic bladder) } \\
\text { - Urethral stricture }\end{array}$ & - Ditto & - Ditto \\
\hline
\end{tabular}


cardiopulmonary bypass (CPB) time $>140 \mathrm{~min}$, and postoperative hypotension ${ }^{[20]}$. The EuroSCORE can be a good predictor for the evaluation of postoperative complications: patients who had postoperative $A K I$ requiring continuous renal replacement therapy showed a higher mean EuroSCORE (8 vs. 4, $P<0.001)$ than controls $^{[21]}$. Moreover, fresh frozen plasma transfusion ${ }^{[22]}$, blood transfusion ${ }^{[23]}$, and preoperative use of angiotensin-converting enzyme inhibitor ${ }^{[24]}$, can be alternative risk factors of postoperative AKl. Some bioactive substances in the fresh frozen plasma, including histamine, eosinophil cationic protein, eosinophil protein $X$, myeloperoxidase, and plasminogen activator inhibitor, enhance the immune response and inflammatory processes, thereby triggering the occurrence of $\mathrm{AKI}^{[22]}$.

The impact of CPB as well as its sequelae plays an important role in triggering postoperative AKI. Suen et al. ${ }^{[25]}$ observed that significant risk factors were preoperative renal insufficiency, postoperative hypotension, CPB time >140 min, preoperative congestive heart failure, and diabetes mellitus. The predictive risk factors in patients undergoing $C A B G$ were postoperative hypotension, CPB time >140 min, preoperative renal insufficiency, and age. During CPB, the non-physiological state of CPB triggers inflammatory cascades and coagulation disorders that affect renal function, and the episodes of emboli can be a potential risk factor for renal infarctions and subsequent reductions in renal function ${ }^{[26]}$. It was once doubtful whether CPB protected renal function during CABG, but less common dialysis requirement in patients receiving off-pump coronary artery bypass offered a dissenting opinion [27]. In general, preoperative renal insufficiency and postoperative hypotension are the most important independent risk factors for AKI in patients after cardiac surgery. A conceptual model of pathophysiology of AKI after cardiac surgery is shown in Figure 1.

\section{Biomarkers}

Except for the conventional indicators, such as serum creatine, GFR, and cystin C, etc., a series of novel biomarkers have been favored in the assessment of AKI after cardiac surgery. These biomarkers, including urinary liver-type fatty acid binding protein (L-FABP), urinary neutrophil gelatinase-associated lipocalin (NGAL), and serum L-FABP, slightly increased in patients who did not develop AKI after cardiac surgery, but the increments were significant in patients with postoperative AKI (Figure 2) [28]. It was demonstrated that urinary L-FABP closely correlated to renal ischemia, namely, peritubular capillary ischemia, and might predict and survey the progression and prognosis of renal disorder, and therefore it was regarded as a reliable indicator of $A K I$, which precedes serum creatinine by hours to days ${ }^{[28]}$. The NGAL is an early indicator of renal ischemia and toxic injuries, and it is remarkably increased in both serum and urine in cases of $A K{ }^{[29]}$. Pickering et al. ${ }^{[30]}$ defined the cutoff for structural AKI as a urinary NGAL concentration $>18.7 \mathrm{ng} / \mathrm{mL}$. The areas under curve (AUCs) of plasma NGAL were 0.74 for the diagnosis of functional AKI, 0.79 for the diagnosis of structural AKI, 0.79 for the diagnosis of $\mathrm{AKI}$ and for prediction of renal replacement therapy, and 0.58 for the prediction of death.

L-FABP, a 14-kDa fatty acid binding protein, is elevated and secreted into the urine as a result of reactive oxygen stress due to renal ischemia. It has been used as a biomarker for the early detection of AKI after cardiac surgery. Urinary L-FABP levels were $601.5 \pm 341.7$ and $233.8 \pm 127.2 \mu \mathrm{g} / \mathrm{g} \mathrm{Cr}$ in the AKI and non-AKI groups, respectively, at the end of surgery. Three hours after surgery, urinary NGAL levels were $950.5 \pm 827.9$ and $430.0 \pm 250.6$ $\mu \mathrm{g} / \mathrm{g} \mathrm{Cr}$ in the $\mathrm{AKI}$ and non-AKI groups, respectively $(P<0.05)^{[31]}$.

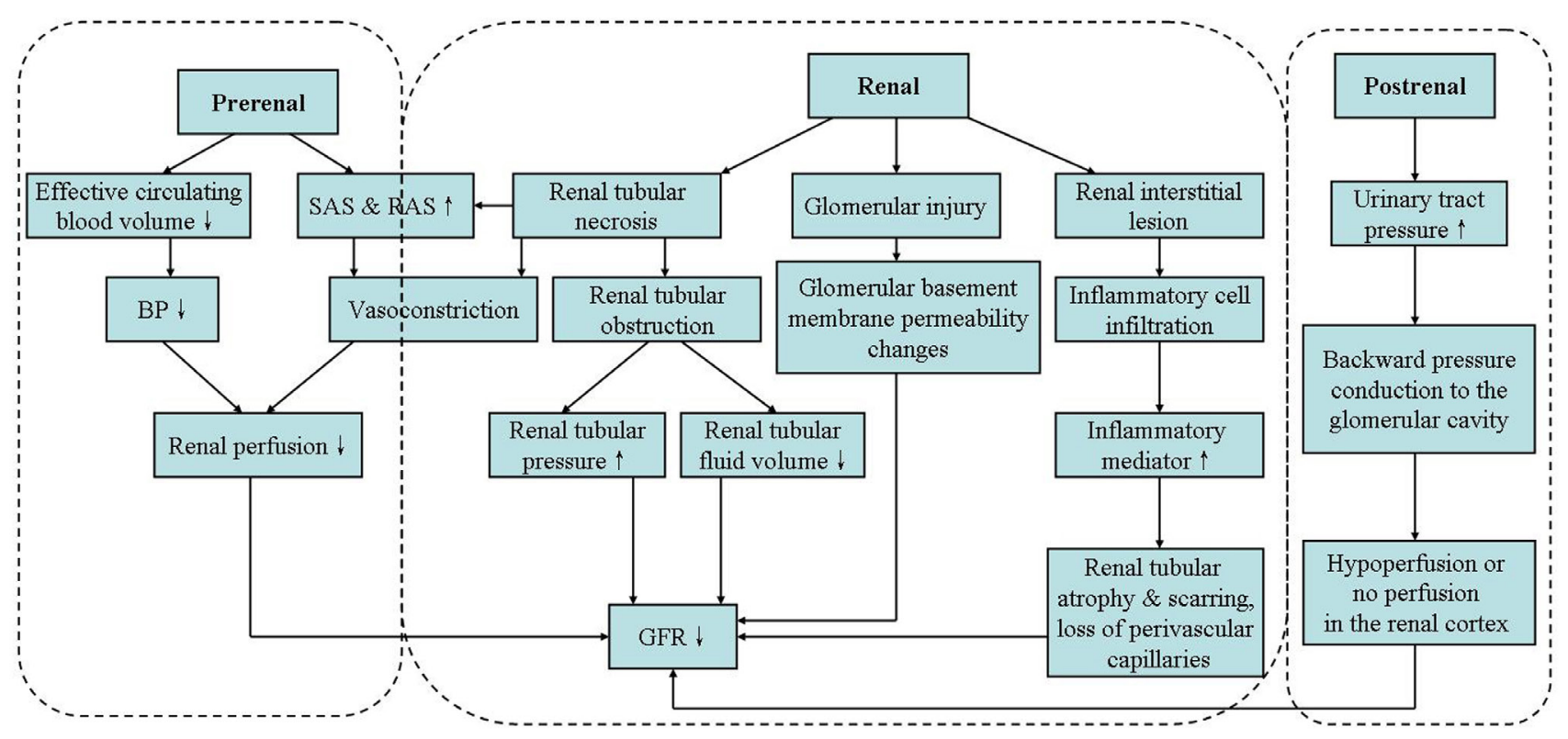

Fig. 1 - A conceptual model of the pathophysiology of acute kidney injury after cardiac surgery.

$B P=$ blood pressure; GFR=glomerular filtration rate; $R A S=$ renin-angiotensin system; $S A S=$ sympathetic-adrenomedullary system 
Heart-type FABP (h-FABP) is a biomarker for myocardial ischemia and is associated with electrocardiogram changes, arrhythmias, and mortality after cardiac surgery. h-FABP and log(h-FABP) levels were discovered to correlate with the severity of $A K I$, and one unit

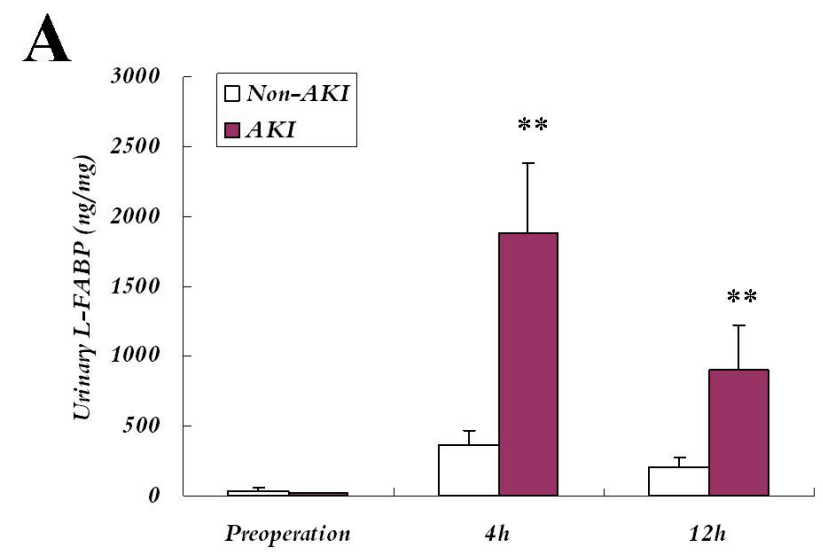

B

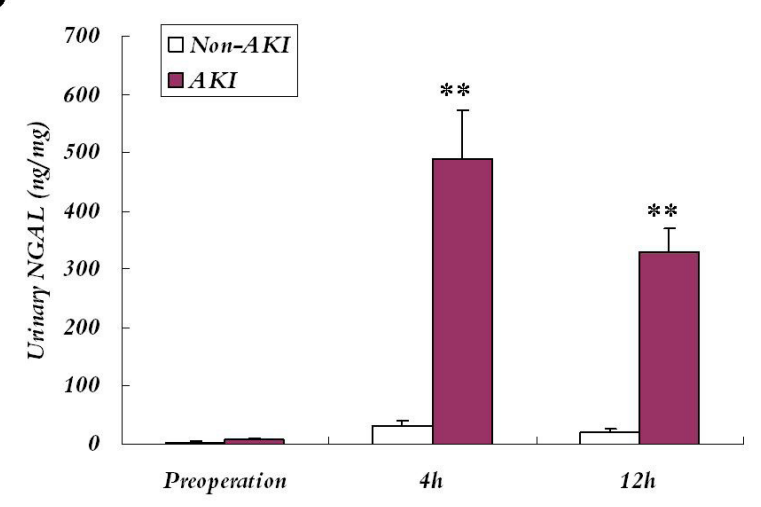

\section{C}

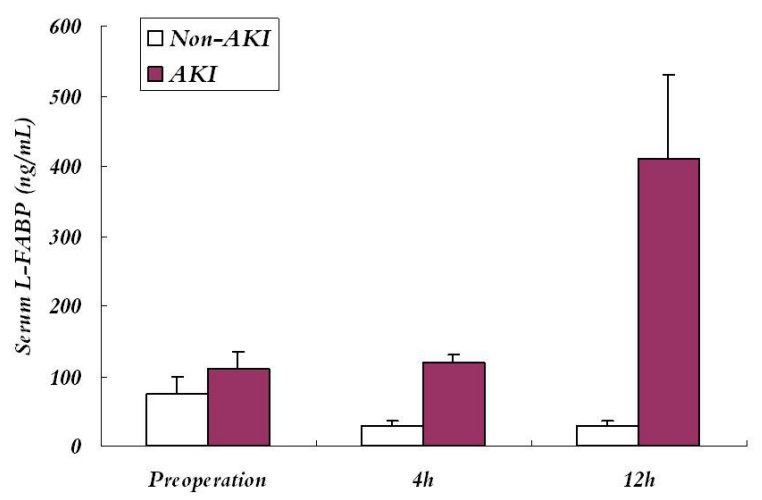

Fig. 2 - A comparison of novel biomarkers between acute kidney injury (AKI) and non-AKI patients: $(A)$ urinary $L-F A B P,(B)$ urinary NGAL, and (C) serum L-FABP were significantly higher in AKI than in non-AKI patients at 4 and 12 hours postoperatively.

${ }^{*} P<0.01$ between $A K I$ and non-AKI patients.

$L$-FABP=liver-type fatty acid binding protein; $N G A L=$ neutrophil gelatinase-associated lipocalin increase in $\log (\mathrm{h}-\mathrm{FABP})$ was associated with a threefold increase in the odds of developing AKI ${ }^{[32,33]}$. Oezkur et al. ${ }^{[34]}$ reported that h-FABP was much higher in the AKI than in the non-AKI group ( $2.9 \mathrm{ng} / \mathrm{mL}$ vs. $1.7 \mathrm{ng} / \mathrm{mL}, P=0.04)$. Preoperative $\mathrm{h}-\mathrm{FABP}$ correlated closely with the length of intensive care unit stay $(r=0.32$, $P=0.007)$ and with duration of hospitalization $(r=0.308, P=0.009)$. Moreover, h-FABP was significantly associated with preoperative creatinine, eGFR, and myoglobin levels.

Kidney injury molecule 1 (KIM-1) is a type-1 transmembrane glycoprotein typically expressed in the proximal tubule cells in ischemic and nephrotoxic conditions. Pediatric patients undergoing cardiac surgery with AKI had higher levels of KIM-1 than the controls, and 12,24, and 36 hours after CPB, the AUCs for the diagnosis of AKI by using KIM-1 were $0.83,0.78$, and 0.84 , respectively ${ }^{[35]}$. As reported by Parikh et al. ${ }^{[36]}$, postoperative KIM-1 levels were significantly increased in comparison to preoperative baselines in both adult and pediatric patients (Figure 3). But KIM-1 was noted to be of no value in predicting progression of the renal disease as L-FABP ${ }^{[36]}$. Instead, urinary KIM-1 levels predicted dialysis requirement and mortality ${ }^{[37]}$. However, Parikh et al. ${ }^{[36]}$ indicated that KIM-1 functions to predict progression of $\mathrm{AKI}$ and adverse outcomes (dialysis requirement and death).

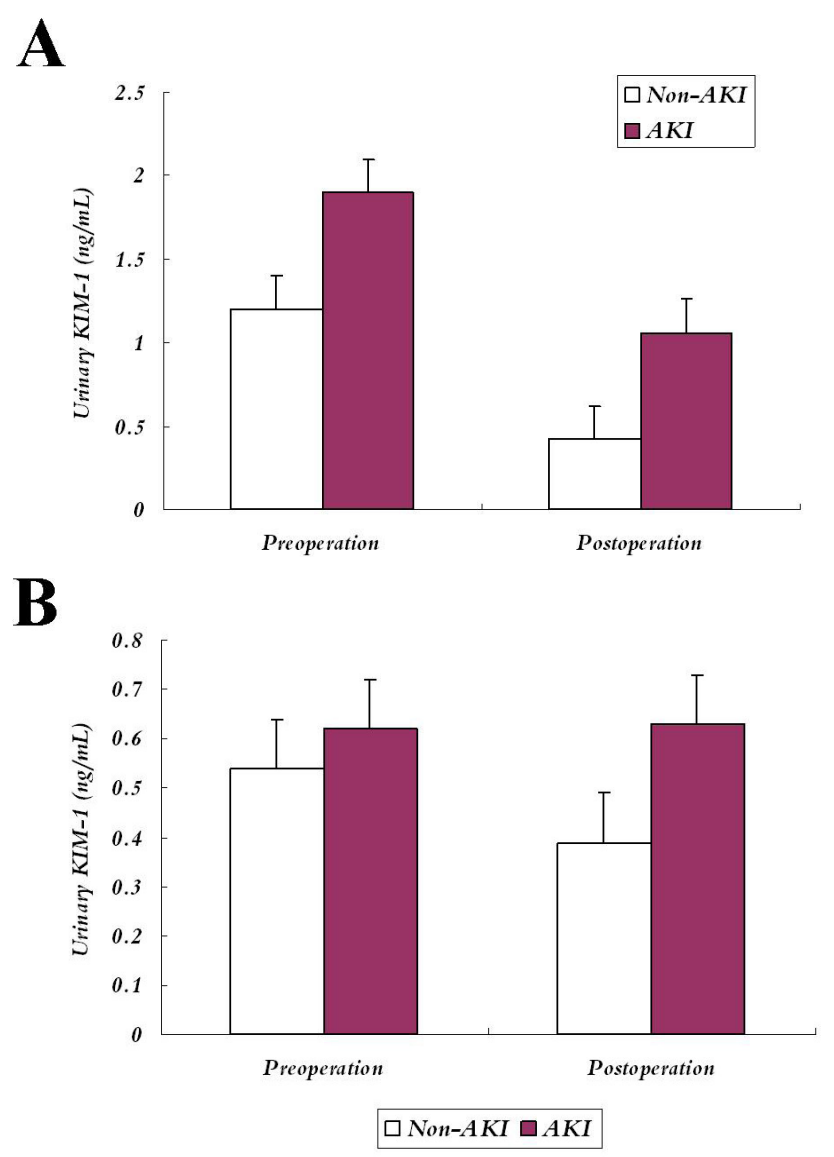

Fig. 3 - A comparison of kidney injury molecule 1 (KIM-1) between acute kidney injury (AKI) and non-AKI patients during postoperative period: $(A)$ in adult and $(B)$ in pediatric patients. ${ }^{*} P<0.05$ between $A K I$ and non-AKI patients. 
They also proposed combined biomarkers (urine KIM-1 on day 1 plus plasma NGAL on day 2, or urine KIM-1 on day 1 plus urine interleukin [IL]-18 on day 2 plus plasma NGAL on day 3) for more accurate predictive outcomes.

Urinary IL-18 levels were significantly increased in patients with AKI compared to controls. Also, urinary IL-18 was increased in kidney transplant patients who had delayed kidney graft function ${ }^{[38]}$. Parikh et al. ${ }^{[39]}$ observed that IL-18 increased $4-6$ hours after CPB, peaked at a 25 -fold increase at 12 hours, and remained markedly elevated up to 48 hours after CPB; urinary NGAL at 4 hours and IL-18 at 4 hours had the best correlation with days of AKI. They suggested that IL-18 is an early, predictive biomarker of AKI after CPB. However, in a single-centre prospective observational cohort study, Haase et al. ${ }^{[40]}$ proposed a dissenting opinion and argued that IL-18 is useless for predict AKI as they noted that urinary IL-18 at 24 hours postoperatively in patients who developed AKI after cardiac surgery was not different from that of non-AKI patients.

Two biomarkers, tissue inhibitor of metalloproteinases-2 (TIMP-2) and insulin-like growth factor binding protein 7 (IGFBP7), are both inducers of the G1 cell cycle arrest and have recently been applied in clinical practice for the early detection of AKI in critical patients ${ }^{[41]}$. Analyses of [TIMP-2]* [IGFBP7] on day 1 after transaortic aortic valve implantation revealed a sensitivity of $100 \%$ and a specificity of $90 \%$ for predicting AKI 2/3. Patients with urinary [TIMP-2]*[IGFBP7] $>0.3$ had seven times the risk for $\mathrm{AKI}$ compared to those critical patients with a result $<0.3^{[41]}$.

Plasma growth-differentiation factor-15 (GDF-15) can be significantly higher in patients with AKI than in those without it ${ }^{[42]}$. Heringlake et al. ${ }^{[42]}$ proposed that the plasma level of GDF15 was a postoperative predictive indicator of AKI. This indicator also predicts postoperative mortality and stratifies patients' risks. However, further investigations are required.

\section{TREATMENT}

\section{Pharmaceutical Strategies}

Diuretics (e.g., mannitol and furosemide): The rationale of AKI treatment by improving renal blood flow and reducing tubular reabsorption is a logical approach for the prevention of outer medullary hypoxic injury. The loop diuretic furosemide acts on the sodium-chloride-potassium co-transporters at the intraluminal side of the ascending limb of the loop of Henle ${ }^{[43]}$. It has been shown to reduce medullary demand by inhibiting solute reabsorption and to attenuate the severity of AKI in animal models ${ }^{[44]}$. Furosemide can increase urine output without improving the creatinine clearance, renal function, and ototoxicity from furosemide because the clearance of furosemide increases the precipitation of urinary glycoprotein by inducing aciduria ${ }^{[43]}$. Treatment with mannitol in patients with cardiac surgery may increase urine flow by $61 \%$, increase renal blood flow by $12 \%$, and decrease renal vascular resistance by $13 \%[45]$.

Vasoactive agents (e.g., calcium channel blockers and atrial natriuretic peptide): The protective effect of calcium channel blockers on both the ischemic and nephrotoxic models of AKI is a potential role for cellular and mitochondrial calcium overload during reperfusion ${ }^{[46]}$. In healthy volunteers and in patients after cardiac surgery with normal renal function, the natriuretic response to atrial natriuretic peptide is associated with an increase in the GFR as evidenced by the majority of studies. At a normal infusion rate, the GFR and filtration fraction increase by 5-35\% and 20-60\%, respectively. In ischemic AKI, atrial natriuretic peptide preferentially induces a reduction in preglomerular resistance. Atrial natriuretic peptide plays an important part in the afferent arterioles in terms of its renal vasodilatory effect in clinically ischemic acute renal failure ${ }^{[47]}$.

Dopamine: Low-dose $(1-3 \mu \mathrm{g} / \mathrm{kg} / \mathrm{min})$ dopamine can increase the renal perfusion of critically ill patients ${ }^{[48]}$. However, it was reported that a continuous intravenous infusion of low-dose dopamine $(2 \mu \mathrm{g} / \mathrm{kg} / \mathrm{min})$ did not show significant protection from renal dysfunction ${ }^{[49]}$. Recent studies have indicated that low-dose dopamine may also be deleterious as a result of inducing renal failure as it may reduce splanchnic perfusion, depress respiration, suppress anterior pituitary hormone release and function, and worsen renal function in hypovolemic or normovolemic patients ${ }^{[50]}$.

Dopamine receptors (dopamine-1 and dopamine-2): Selective dopamine-1 agonists have many desirable renal effects that theoretically support their use for the prophylaxis and (or) treatment of AKI for decreasing renal vascular resistance and increasing sodium excretion and urine volume. Even at high doses, some selective dopamine-1 agonists, such as fenoldopam, do not stimulate dopamine-2 receptors, or adrenergic a- or $\beta$-receptors, and therefore they are free of unwanted side effects (e.g., arrhythmias $)^{[51]}$. Selective dopamine-1 receptor agonists exhibit many renal effects in decreasing renal vascular resistance and increasing renal blood flow, glomerular filtration, and sodium and water excretion ${ }^{[52]}$.

Steroids: Steroid therapy (prednisolone $1 \mathrm{mg} / \mathrm{kg}$ for 1 month, tapered off $0.1 \mathrm{mg} / \mathrm{kg}$ every two weeks) in patients with moderate renal failure and evidence of renal functional deterioration retards the progression of renal failure characterized by an interstitial fibrosis ${ }^{[53]}$. However, the anti-inflammatory agents, such as dexamethasone, administrated before the start of CPB, showed no protective effect on perioperative renal dysfunction in low-risk cardiac surgical patients ${ }^{[54]}$.

Antioxidant ( $\mathrm{N}$-acetylcysteine [NAC]): NAC does not reduce the extent of proximal tubule necrosis in 24 hours after reperfusion but may improve the histological appearance of the kidney in 7 days. This improvement of renal function impairment may be attributable to the NAC antioxidant effect or possible interactions between NAC and nitric oxide ${ }^{[55]}$, and it can decrease the creatinine level significantly after the treatment ${ }^{[56]}$. However, Adabag et al. ${ }^{[57]}$ raised a different opinion, that prophylactic NAC management prior to cardiac surgery did not reduce AKI incidence or decrease serum creatinine after surgery. In a recent prospective randomized study, Amini et al. ${ }^{[58]}$ found out that perioperative use of NAC, vitamin $C$, and selenium, did not reduce the risk of AKI following off-pump coronary artery bypass procedure.

\section{Renal Replacement Therapy}

The internal jugular and femoral veins are the usual venous accesses for cannulations of renal replacement therapy. The 
dialysate solution is $1.36 \%$ peritoneal dialysis fluid. Blood and dialysate flow rates are kept at 100-150 mL/min and $1 \mathrm{~L} /$ hour, respectively. Low molecular weight heparin is used during the procedure and the target level of activated coagulation time is maintained at 180-200 seconds. Meanwhile, the ultrafiltration rate is adjusted between 35 and $45 \mathrm{~mL} / \mathrm{kg} / \mathrm{hour}^{[59]}$.

Early start of dialysis is extremely important for improving the outcomes of the patients. An early dialysis means that the dialysis starts within 24 hours after cardiac operation, when the patient is in a stable hemodynamic status without oblivious cardiac dysfunction; while the late dialysis usually starts 24 hours after cardiac operation, when the patient is in an unstable hemodynamic condition with further impaired heart function ${ }^{[10]}$.

\section{Prognosis}

Patients with postoperative AKI were associated with a much higher mortality rate in comparison to those without it (18.8\% vs. 2.1\%). It has been shown that the mortality was $50 \%$ in the patients who needed dialysis ${ }^{[60]}$. Silva et al. ${ }^{[61]}$ proved in a retrospective study that AKI patients requiring dialysis during postoperative period were a risk factor of late mortality. Zheng et al. ${ }^{[9]}$ reported that patients with oliguresis of 3 hours showed a higher drug cure rate and a lower mortality rate than those with oliguresis $>5-6$ hours (drug cure rate: $75.8 \%$ vs. $17.6 \%$; mortality rate: $3.0 \%$ vs. $47.1 \%$; respectively). Han et al. ${ }^{[18]}$ found out that the survival rate of patients with oliguric AKI was significantly lower than of those with non-oliguric AKI. Oliguric AKI, along with sustained hypotension, number of failure organs, and dialysis requirement, was a risk factor closely related to mortality. Demirkiliç et al. ${ }^{[59]}$ reported that continuous venovenous hemodiafiltration was used in patients with creatinine level $>5 \mathrm{mg} / \mathrm{dL}$ or potassium level $>5.5 \mathrm{mEq} / \mathrm{L}$, with no response to diuretics. The intensive care unit mortality rate was $48.1 \%$ for patients with an early start dialysis on day $0.88 \pm 0.33$ and $17.6 \%$ for those with a late start dialysis on day $2.56 \pm 1.67$. Thus, an early dialysis for AKl after cardiac surgery is associated with significant lower hospital mortality.

Pediatric patients with postoperative AKI following correction of congenital heart defect under CPB can be treated by peritoneal dialysi ${ }^{[62]}$. In such patient population with renal replacement therapy, the mortality rate varied between 33\% and $70 \%$. This occurred because children have immaturely developed organ system, with poor physiological reserve and compensatory ability, and impaired tolerance to ischemia and hypoxia. Comparative studies revealed that continuous arteriovenous hemofiltration and continuous venovenous hemofiltration were mostly used in adults, requiring additional blood circuit and system heparinization; while peritoneal dialysis was commonly used for infantile AKI, but no significance was noted in the mortality rates between these groups. Peritoneal dialysis can remove excess water from the body and adjust disturbance of water and electrolyte and acid-base imbalance. Also, peritoneal dialysis shows little influence on hemodynamics, particularly on low output syndrome after open heart surgery, as this kind of dialysis does not require cannulation and systemic heparinization. Peritoneal dialysis is extremely suitable for AKI after open heart surgery in children for renal replacement therapy as for the simple devices and fewer maneuver requirements ${ }^{[63]}$.

\section{CONCLUSION}

In patients with AKI after cardiac surgery, novel biomarkers have been recognized as reliable indicators for diagnosis, predicting the adverse outcome, and even mortality of postoperative AKI. Renal replacement therapy should start early to achieve a promising prognosis. In children, AKI after cardiac surgery can be managed with peritoneal dialysis, which may benefit them with better hemodynamic stability.

\section{No financial support. No conflict of interest.}

\section{REFERENCES}

1. Bove T, Calabrò MG, Landoni G, Aletti G, Marino G, Crescenzi G, et al. The incidence and risk of acute renal failure after cardiac surgery. J Cardiothorac Vasc Anesth. 2004;18(4):442-5. doi: 10.1053/j.jvca.2004.05.021.

2. Stallwood MI, Grayson AD, Mills K, Scawn ND. Acute renal failure in coronary artery bypass surgery: independent effect of cardiopulmonary bypass. Ann Thorac Surg. 2004;77(3):968-72. doi:10.1016/j.athoracsur.2003.09.063.

3. Nicoara A, Patel UD, Phillips-Bute BG, Shaw AD, Stafford-Smith M, Milano $C A$, et al. Mortality trends associated with acute renal failure requiring dialysis after CABG surgery in the United States. Blood Purif. 2009;28(4):35963. doi:10.1159/000235856.

4. Barbosa RR, Cestari PF, Capeletti JT, Peres GM, Ibañez TL, da Silva PV, et al. Impact of renal failure on in-hospital outcomes after coronary artery bypass surgery. Arq Bras Cardiol. 2011;97(3):249-53. doi: 10.1590/S0066782X2011005000075.

5. King KB, Clark PC, Norsen LH, Hicks GL Jr. Coronary artery bypass graft surgery in older women and men. Am J Crit Care [Internet]. 1992 [cited 2019 Apr 25];1 (2):28-35. Available from: https://www.ncbi.n/m.nih.gov/ pubmed/1307888.

6. Gargiulo G, Sannino A, Capodanno D, Barbanti M, Buccheri S, Perrino C, et al. Transcatheter aortic valve implantation versus surgical aortic valve replacement: a systematic review and meta-analysis. Ann Intern Med. 2016;165(5):334-44. doi:10.7326/M16-0060.

7. Ko T, Higashitani M, Sato A, Uemura Y, NorimatsuT, Mahara K, et al. Impact of acute kidney injury on early to long-term outcomes in patients who underwent surgery for type A acute aortic dissection. Am J Cardiol. 2015;116(3):463-8. doi:10.1016/j.amjcard.2015.04.043.

8. Ng RR, Tan GH, Liu W, Ti LK, Chew ST. The association of acute kidney injury and atrial fibrillation after cardiac surgery in an Asian prospective cohort study. Medicine (Baltimore). 2016;95(12):e3005. doi:10.1097/ MD.0000000000003005

9. Zheng ZF, Qiu ZK, Gong BS, Ren SN. Treatment of acute renal failure complicating cardiac surgery. Shanghai Med J. 2002;25(1):29-32. 
10. Brown JR, Cochran RP, Leavitt BJ, Dacey LJ, Ross CS, MacKenzie TA, et al. Multivariable prediction of renal insufficiency developing after cardiac surgery. Circulation. 2007;116(11 Suppl):1139-43.doi:10.1161/ CIRCULATIONAHA. 106.677070.

11. Abelha FJ, Botelho M, Fernandes V, Barros H. Determinants of postoperative acute kidney injury. Crit Care. 2009;13(3):R79. doi:10.1186/cc7894.

12. Mysliwiec P, Jasiewicz P, Hady HR, Choromanska B, Mroczko B, Mysliwiec $\mathrm{H}$, et al. Creatinine or cystatin $\mathrm{C}$ - which is a better index of renal function in morbid obesity? Adv Med Sci. 2013;58(2):376-81. doi:10.2478/ams2013-0020.

13. Lopes JA, Fernandes P, Jorge S, Gonçalves S, Alvarez A, Costa e Silva Z, et al. Acute kidney injury in intensive care unit patients: a comparison between the RIFLE and the Acute Kidney Injury Network classifications. Crit Care. 2008;12(4):R110. doi:10.1186/cc6997.

14. Machado MN, Nakazone MA, Maia LN. Prognostic value of acute kidney injury after cardiac surgery according to kidney disease: improving global outcomes definition and staging (KDIGO) criteria. PLoS One. 2014;9(5):e98028. doi: 10.1371/journal.pone.0098028.

15. Chang CH, Fu CM, Yang CH, Fan PC, Li PC, Hsu GY, et al. Society of Thoracic Surgeons score predicts kidney injury in patients not undergoing bypass surgery. Ann Thorac Surg. 2015;99(1):123-9. doi: 10.1016/j. athoracsur.2014.07.072.

16. Rosner MH, Okusa MD. Acute kidney injury associated with cardiac surgery. Clin J Am Soc Nephrol. 2006;1 (1):19-32. doi: 10.2215/CJN.00240605.

17. Jutila K. What are the causes of an acute renal failure after open heart surgery? [Internet]. Official Partner of the Livestrong Foundation [Last Updated: 2015 Oct 20]. [cited 2015 Nov 2]. Available from: http://www. livestrong.com/article/258950-what-are-the-causes-of-an-acute-renalfailure-after-open-heart-surgery/

18. Han GF, Zhang JY, Lu S, Li YZ. Etiological and prognostic factors in patients with acute renal failure after cardiac surgery. Chin J Blood Purific. 2005;4(6):302-5.

19. Brown JR, Cochran RP, Leavitt BJ, Dacey LJ, Ross CS, MacKenzie TA, et al; Northern New England Cardiovascular Disease Study Group. Multivariable prediction of renal insufficiency developing after cardiac surgery. Circulation. 2007;116(11 Suppl):1139-43.

20. Reddy VG. Prevention of postoperative acute renal failure. J Postgrad Med [Internet]. 2002 [cited 2019 Apr 27];48(1):64-70. Available from: http:// www.jpgmonline.com/text.asp?2002/48/1/64/148.

21. Doddakula K, Al-Sarraf N, Gately K, Hughes A, Tolan M, Young V, et al. Predictors of acute renal failure requiring renal replacement therapy post cardiac surgery in patients with preoperatively normal renal function. Interact Cardiovasc Thorac Surg. 2007;6(3):314-8. doi:10.1510/ icvts.2006.148874.

22. Godet G, Fléron MH, Vicaut E, Zubicki A, Bertrand M, Riou B, et al. Risk factors for acute postoperative renal failure in thoracic or thoracoabdominal aortic surgery: a prospective study. Anesth Analg [Internet]. 1997 [cited 2019 Apr 27];85(6):1227-32. Available from: https://www.ncbi.nlm.nih. gov/pubmed/9390585.

23. Rawn JD. Blood transfusion in cardiac surgery: a silent epidemic revisited. Circulation. 2007;116(22):2523-4. doi:10.1161/ CIRCULATIONAHA.107.739094.

24. Schoolwerth AC, Sica DA, Ballermann BJ, Wilcox CS; Council on the Kidney in Cardiovascular Disease and the Council for High Blood Pressure Research of the American Heart Association. Renal considerations in angiotensin converting enzyme inhibitor therapy: a statement for healthcare professionals from the Council on the Kidney in Cardiovascular Disease and the Council for High Blood Pressure Research of the American Heart Association. Circulation. 2001;104(16):1985-91. doi:10.1161/ hc4101.096153.

25. Suen WS, Mok CK, Chiu SW, Cheung KL, Lee WT, Cheung D, et al. Risk factors for development of acute renal failure (ARF) requiring dialysis in patients undergoing cardiac surgery. Angiology. 1998;49(10):789-800. doi:10.1177/000331979804900902.

26. Aydin S, Dogra S, Del Rio M. Acute Kidney Injury. In: da Cruz E, Ivy D, Jaggers J, editors. Pediatric and Congenital Cardiology, Cardiac Surgery and Intensive Care. London:Springer-Verlag; 2019; p. 3257-77. doi:10.1007/9781-4471-4619-3_174.

27. Reston JT, Tregear SJ, Turkelson CM. Meta-analysis of short-term and mid-term outcomes following off-pump coronary artery bypass grafting. Ann Thorac Surg. 2003;76(5):1510-5. doi:10.1016/S0003-4975(03)01195-0.

28. Portilla D, Dent C, Sugaya T, Nagothu KK, Kundi I, Moore P, et al. Liver fatty acid-binding protein as a biomarker of acute kidney injury after cardiac surgery. Kidney Int. 2008;73(4):465-72. doi:10.1038/sj.ki.5002721.

29. Cruz DN, Ronco C, Katz N. Neutrophil gelatinase-associated lipocalin: a promising biomarker for detecting cardiac surgery-associated acute kidney injury. JThorac Cardiovasc Surg. 2010;139(5):1101-6. doi:10.1016/j. jtcvs.2009.11.007.

30. Pickering JW, Endre ZH. The clinical utility of plasma neutrophil gelatinaseassociated lipocalin in acute kidney injury. Blood Purif. 2013;35(4):295-302. doi: $10.1159 / 000351542$.

31. Moriyama T, Hagihara S, Shiramomo T, Nagaoka M, Iwakawa S, Kanmura Y. Comparison of three early biomarkers for acute kidney injury after cardiac surgery under cardiopulmonary bypass. J Intensive Care. 2016;4:41. doi:10.1186/s40560-016-0164-1.

32. Bucholz EM, Whitlock RP, Zappitelli M, Devarajan P, Eikelboom J, Garg AX, et al; TRIBE-AKI Consortium. Cardiac biomarkers and acute kidney injury after cardiac surgery. Pediatrics [Internet]. 2015 [cited 2019 Apr 27];135(4):e945-56. Available from: https://pediatrics.aappublications. org/content/pediatrics/135/4/e945.full.pdf.

33. Schaub JA, Garg AX, Coca SG, Testani JM, Shlipak MG, Eikelboom J, et al; TRIBE-AKI Consortium. Perioperative heart-type fatty acid binding protein is associated with acute kidney injury after cardiac surgery. Kidney Int. 2015;88(3):576-83. doi:10.1038/ki.2015.104.

34. Oezkur M, Gorski A, Peltz J, Wagner M, Lazariotou M, Schimmer C, et al. Preoperative serum h-FABP concentration is associated with postoperative incidence of acute kidney injury in patients undergoing cardiac surgery. BMC Cardiovasc Disord. 2014;14:117. doi:10.1186/1471-2261-14-117.

35. Han WK, Waikar SS, Johnson A, Betensky RA, Dent CL, Devarajan P, et al. Urinary biomarkers in the early diagnosis of acute kidney injury. Kidney Int. 2008;73(7):863-9. doi:10.1038/sj.ki.5002715.

36. Parikh CR, Thiessen-Philbrook H, Garg AX, Kadiyala D, Shlipak MG, Koyner $J \mathrm{~L}$, et al; TRIBE-AKI Consortium. Performance of kidney injury molecule-1 and liver fatty acid-binding protein and combined biomarkers of AKI after cardiac surgery. Clin J Am Soc Nephrol. 2013;8(7):1079-88. doi:10.2215/ CJN.10971012.

37. Liangos O, Perianayagam MC, Vaidya VS, Han WK, Wald R, Tighiouart H, et al. Urinary $\mathrm{N}$-acetyl- $\beta$-(D)-glucosaminidase activity and kidney injury molecule-1 level are associated with adverse outcomes in acute renal failure. J Am Soc Nephrol. 2007;18(3):904-12. doi:10.1681/ASN.2006030221.

38. Parikh CR, Jani A, MelnikovVY, Faubel S, Edelstein CL. Urinary interleukin-18 is a marker of human acute tubular necrosis. Am J Kidney Dis. 2004;43(3):405-14. doi:10.1053/j.ajkd.2003.10.040.

39. Parikh CR, Mishra J, Thiessen-Philbrook H, Dursun B, Ma Q, Kelly C, et al. Urinary IL-18 is an early predictive biomarker of acute kidney injury after cardiac surgery. Kidney Int. 2006;70(1):199-203. doi:10.1038/sj.ki.5001527.

40. Haase M, Bellomo R, Story D, Davenport P, Haase-Fielitz A. Urinary interleukin-18 does not predict acute kidney injury after adult cardiac surgery: a prospective observational cohort study. Crit Care. 2008;12(4):R96. doi:10.1186/cc6972.

41. Dusse F, Edayadiyil-Dudásova M, Thielmann M, Wendt D, Kahlert $P$, Demircioglu $E$, et al. Early prediction of acute kidney injury after transapical and transaortic aortic valve implantation with urinary G1 cell cycle arrest biomarkers. BMC Anesthesiol. 2016;16:76. doi:10.1186/s12871-016-0244-8. 
42. Heringlake $M$, Charitos El, Erber K, Berggreen AE, Heinze H, Paarmann H. Preoperative plasma growth-differentiation factor-15 for prediction of acute kidney injury in patients undergoing cardiac surgery. Crit Care. 2016;20(1):317. doi:10.1186/s13054-016-1482-3.

43. Ho KM, Power BM. Benefits and risks of furosemide in acute kidney injury. Anaesthesia. 2010;65(3):283-93. doi:10.1111/j.1365-2044.2009.06228.x.

44. Davis A, Gooch I. The use of loop diuretics in acute renal failure in critically ill patients to reduce mortality, maintain renal function, or avoid the requirements for renal support. Emerg Med J. 2006;23(7):561-4. doi:10.1136/emj.2006.038513.

45. Bragadottir G, Redfors B, Ricksten SE. Mannitol increases renal blood flow and maintains filtration fraction and oxygenation in postoperative acute kidney injury: a prospective interventional study. Crit Care. 2012;16(4):R159. doi:10.1186/cc11480.

46. Chan L, Schrier RW. Effects of calcium channel blockers on renal function. Annu Rev Med. 1990;41:289-302. doi:10.1146/annurev. me.41.020190.001445.

47. Ricksten SE, Swärd K. Atrial natriuretic peptide in postoperative acute renal failure. In:Vicent JL, editor. Intensive Care and Emergency Medicine. New York:Springer;2010. p. 339-48. doi:10.1007/978-3-642-10286-8_32.

48. Fry AC, Farrington K. Management of acute renal failure. Postgrad Med J. 2006;82(964):106-16. doi:10.1136/pgmj.2005.038588.

49. Bellomo R, Chapman M, Finfer S, Hickling K, Myburgh J. Low-dose dopamine in patients with early renal dysfunction: a placebo-controlled randomised trial. Australian and New Zealand Intensive Care Society (ANZICS) Clinical Trials Group. Lancet. 2000;356(9248):2139-43. doi:10.1016/S0140-6736(00)03495-4.

50. Debaveye YA, Van den Berghe GH. Is there still a place for dopamine in the modern intensive care unit? Anesth Analg. 2004;98(2):461-8. doi:10.1213/01.ANE.0000096188.35789.37.

51. Singer I, Epstein M. Potential of dopamine A-1 agonists in the management of acute renal failure. Am J Kidney Dis. 1998;31(5):743-55. doi:10.1016/ S0272-6386(98)70043-5.

52. Asif A, Epstein DL, Epstein M. Dopamine-1 receptor agonist: renal effects and its potential role in the management of radiocontrastinduced nephropathy. J Clin Pharmacol. 2004;44(12):1342-51. doi:10.1177/0091270004269842.
53. Vanherweghem JL, Abramowicz D, Tielemans C, Depierreux M. Effects of steroids on the progression of renal failure in chronic interstitial renal fibrosis: a pilot study in Chinese herbs nephropathy. Am J Kidney Dis. 1996;27(2):209-15. doi:10.1016/S0272-6386(96)90542-9.

54. Loef BG, Henning RH, Epema AH, Rietman GW, van Oeveren W, Navis GJ, et al. Effect of dexamethasone on perioperative renal function impairment during cardiac surgery with cardiopulmonary bypass. Br J Anaesth. 2004;93(6):793-8. doi:10.1093/bja/aeh266.

55. DiMari J, Megyesi J, Udvarhelyi N, Price P, Davis R, Safirstein R. N-acetyl cysteine ameliorates ischemic renal failure. Am J Physiol. 1997;272(3 Pt 2):F292-8. doi:10.1152/ajprenal.1997.272.3.F292.

56. Bagshaw SM, McAlister FA, Manns BJ, Ghali WA. Acetylcysteine in the prevention of contrast-induced nephropathy: a case study of the pitfalls in the evolution of evidence. Arch Intern Med. 2006;166(2):1616. doi:10.1001/archinte.166.2.161.

57. Adabag AS, Ishani A, Bloomfield HE, Ngo AK, Wilt TJ. Efficacy of $\mathrm{N}$-acetylcysteine in preventing renal injury after heart surgery: a systematic review of randomized trials. Eur Heart J. 2009;30(15):1910-7. doi:10.1093/ eurheartj/ehp053.

58. Amini S, Robabi HN, Tashnizi MA, Vakili V. Selenium, vitamin C and $\mathrm{N}$-acetylcysteine do not reduce the risk of acute kidney injury after off-pump CABG: a randomized clinical trial. Braz J Cardiovasc Surg. 2018;33(2):129-34. doi:10.21470/1678-9741-2017-0071.

59. Demirkiliç U, Kuralay E, Yenicesu M, Cağlar K, Oz BS, Cingöz F, et al. Timing of replacement therapy for acute renal failure after cardiac surgery. J Card Surg. 2004;19(1):17-20. doi:10.1111/j.0886-0440.2004.04004.x.

60. Hashemzadeh K, Hashemzadeh S, Dehdilani M. Risk factors and outcomes of acute renal failure after open cardiac surgery. Asian Cardiovasc Thorac Ann. 2012;20(3):275-280. doi:10.1177/0218492312436402.

61. Silva ABV, Cavalcante AMRZ, Taniguchi FP. Survival and risk factors among dialytic acute kidney injury patients after cardiovascular surgery. Braz J Cardiovasc Surg. 2018;33(3):277-85. doi:10.21470/1678-9741-2017-0184.

62. Chien JC, Hwang BT, Weng ZC, Meng LC, Lee PC. Peritoneal dialysis in infants and children after open heart surgery. Pediatr Neonatol. 2009;50(6):275-9. doi:10.1016/S1875-9572(09)60077-2.

63. Chen H, Wang JW, Yin YM. Peritoneal dialysis after repair of congenital heart disease in children. China Med Pharm. 2011;1 (6):89-90. 